\title{
Welcome New Associate Editor Nancy Baxter of Canada to the World Journal of Surgery
}

\author{
Julie Ann Sosa ${ }^{1}$
}

Published online: 20 May 2019

(C) Société Internationale de Chirurgie 2019

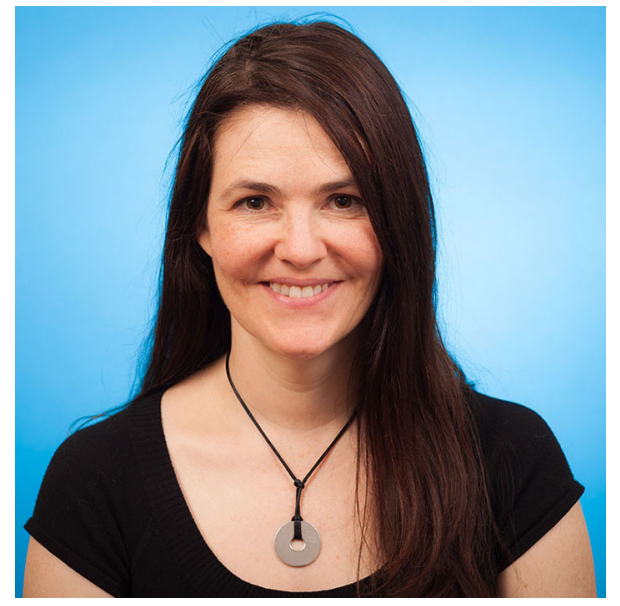

The World Journal of Surgery is thrilled to announce that Nancy Baxter MD, PhD of Toronto, Canada, has joined our team as an internationally renowned associate editor.

Dr Baxter obtained her MD and PhD in Clinical Epidemiology from University of Toronto. She is board-certified in colon and rectal surgery and is a Fellow of the
Association for Colon and Rectal Surgeons. Currently, she is the Head of the Division of General Surgery at St. Michael's Hospital. She holds a Scientist position with the $\mathrm{Li}$ Ka Shing Knowledge Institute and is a Senior Scientist at the Institute for Clinical Evaluative Sciences. Dr. Baxter is also the Associate Dean of Academic Affairs at the Dalla Lana School of Public Health and a Professor in the Department of Surgery and Institute of Health Policy, Management and Evaluation at the University of Toronto. She holds the position of Provincial GI Endoscopy lead for Cancer Care Ontario. Dr Baxter is an accomplished clinical epidemiologist and health services researcher interested in the effectiveness of cancer screening, long-term cancer survivorship, and the quality of surgical care. She has extensive experience in the use of administrative and cancer registry data to evaluate long-term consequences of cancer care for adults.

Dr Baxter will be replacing Dieter Hahnloser MD, head of colorectal surgery at University Hospital Lausanne, Switzerland, who will be rotating off the editorial board after having faithfully served as associate editor since 2009. Thank you, Dieter, and welcome Nancy!

Julie Ann Sosa

julie.sosa@ucsf.edu

1 Department of Surgery, University of California, San Francisco, San Francisco, CA, USA 